\title{
The ANKA-IR2 Nanoscope and Micro- and Nanospectroscopy Applications
}

\author{
E. Bründermann ${ }^{\mathrm{a}}$, D. A. Schmidt ${ }^{\mathrm{b}}$, B. Gasharova ${ }^{\mathrm{c}}$, Y.-L. Mathis ${ }^{\mathrm{d}}$, D. Moss ${ }^{\mathrm{d}}$, J. Steinmann ${ }^{\mathrm{e}}$, \\ E. Edengeiser ${ }^{\mathrm{a}}$, M. Mischo ${ }^{\mathrm{a}}$, and M. Havenith ${ }^{\mathrm{a}}$ \\ ${ }^{\text {a} P h y s i k a l i s c h e ~ C h e m i e ~ I I, ~ R u h r-U n i v e r s i t a ̈ t ~ B o c h u m, ~ N C-N o r d ~ 7 / 72, ~} 44780$ Bochum, Germany \\ ${ }^{b}$ North Carolina A\&T State university, Dept. of Physics, Greensboro, NC 27411 \\ and Joint School of Nanoscience \& Nanoengineering (A\&T \& UNCG), Greensboro, NC 27401, USA \\ ${ }^{c}$ Karlsruhe Institute of Technology, Institute for Photon Science and Synchrotron Radiation (IPS), P.O. Box 3640, 76021 \\ Karlsruhe, Germany \\ ${ }^{\mathrm{d}}$ Karlsruhe Institute of Technology, ANKA Synchrotron Radiation Facility, P.O. Box 3640, 76021 Karlsruhe, Germany \\ ${ }^{\mathrm{e}}$ Karlsruhe Institute of Technology, Laboratory for Applications of Synchrotron radiation (LAS), P.O. Box 3640, 76021 \\ Karlsruhe, Germany
}

\begin{abstract}
We report on a newly developed and integrated microscopy and nanoscopy station at the ANKA-IR2 beamline. We further elucidate how vibrational near-field and microspectroscopy can give new insights in medical applications.
\end{abstract}

\section{INTRODUCTION AND BACKGROUND}

$\mathrm{A}$ novel microscopy and nanoscopy station integrated at the ANKA-IR2 synchrotron beamline ${ }^{1}$ (Fig. 1) combines farand near-field spectroscopy and microscopy ${ }^{1,2}$ with a variety of other modalities such as: Raman confocal and atomic force microscopy $(\mathrm{AFM})^{1-3,5}$, near-field aperture (a-SNOM) ${ }^{1}$ and aperture-less or scattering near-field optical microscopy (sSNOM) ${ }^{1-3,6}$ in the IR and THz region ${ }^{7}$.

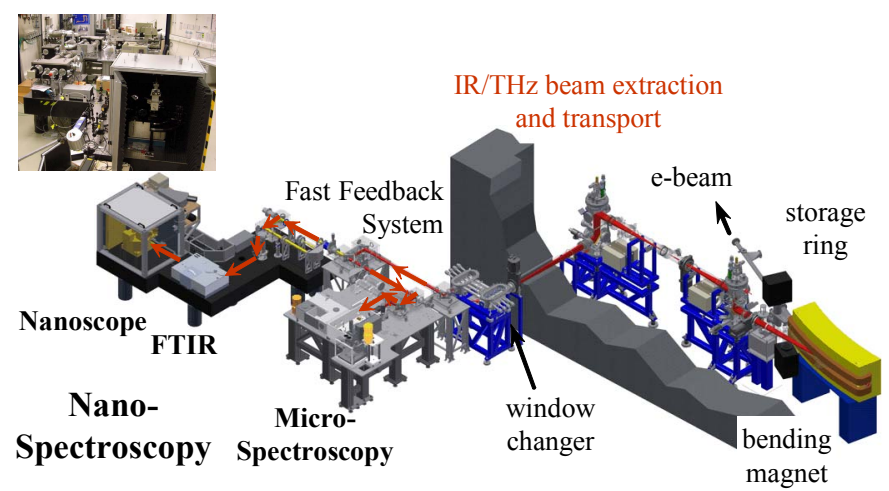

Fig. 1: Nano- and micro-spectroscopy stations at the ANKA-IR2 beamline (photo: view at the multi-modal microscope). They are connected via a versatile window changer and fast feedback system for the optical beam.

The multi-modal nanoscope is designed to combine a broad array of techniques to study the "same" sample at the "same" position $^{3,5}$, e.g. semiconductors ${ }^{3}$ or graphene, ${ }^{5}$ using $\operatorname{IR}^{3}$ and $\mathrm{THz}$ synchrotron radiation ${ }^{4}$.

\section{RESULTS}

We report on near-field microscopy applications in the infrared and on the development of time-resolved detection techniques in the $\mathrm{THz}$ spectral range. Figure 2 shows a measurement of scattered infrared light from a sample illuminated by one of the additional offline laser sources. The optical beam was passed through the FTIR and focused on the AFM cantilever tip, which oscillates at a sub-MHz frequency $f$. The scattered light was detected with an IR detector and demodulated with a lock-in amplifier at $2 f$, a typical operating mode to record near-field images.

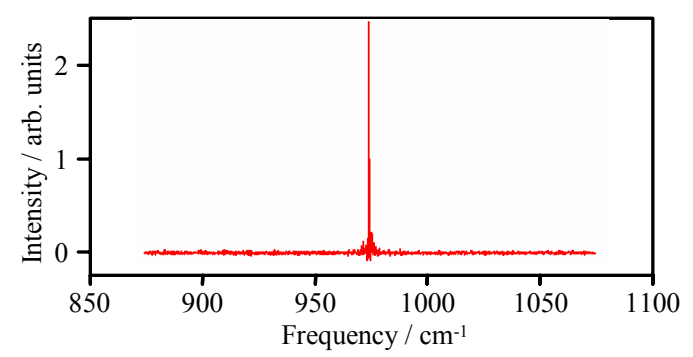

Fig. 2: FTIR measurement of scattered light from a sample illuminated at $975 \mathrm{~cm}^{-1}(29 \mathrm{THz})$ and demodulated at $2 f$ of the cantilever oscillation frequency $f$.

We further elucidate how vibrational micro-spectroscopy can give new insights in chemistry and medicine ${ }^{2,6}$. Introducing infrared active labels ${ }^{6}$ into super-resolution IR sSNOM may enable molecular tracking and distribution studies even in complex biological systems ${ }^{6}$.

\section{ACKNOWLEDGMENTS}

The project is supported by BMBF under grants 05KS7PC2 and $05 \mathrm{~K} 10 \mathrm{PCA}$. The authors appreciate the beam time made available at ANKA (Karlsruhe, Germany) and thank for the support by the ANKA team.

\section{REFERENCES}

[1] D.A. Schmidt, E. Bründermann, M. Havenith, "Combined farand near-field chemical nanoscope at ANKA-IR2: applications and detection schemes", J. Phys.: Conf. Series 359, pp. 012015$1-012015-8,2012$.

[2] D. A. Schmidt, I. Kopf, E. Bründermann, "A matter of scale: from far-field microscopy to near-field nanoscopy", Laser \& Photonics Reviews 6(3), pp. 296-332, 2012.

[3] F. Ballout, J.-S. Samson, D.A. Schmidt, E. Bründermann, Y.-L. Mathis, B. Gasharova, A. D. Wieck, M. Havenith, "NonInvasive Nano-Imaging of Ion Implanted and Activated Copper in Silicon", J. Appl. Phys. 110(2), pp. 024307-1-024307-7, 2011. 
[4] A.-S. Müller, N. Hiller, A. Hofmann, E. Huttel, , K. Il'in, V. Judin, B. Kehrer, M. Klein, S. Marsching, C. Meuter, S. Naknaimueang, M.J. Nasse, A. Plech, P. Probst, A. Scheuring, M. Schuh, M. Schwarz, M. Siegel, N. Smale, M. Streichert, F. Caspers, A. Semenov, H.-W. Hübers, E. Bründermann, "Experimental Aspects of CSR in the ANKA Storage Ring", ICFA Beam Dyn. Newslett., vol. 57, pp. 154-165, 2012.

[5] D. A. Schmidt, T. Ohta, T. E. Beechem, "Strain and charge carrier coupling in epitaxial graphene", Phys. Rev. B 84 (23), 235422-1 - 235422-8, 2011.

[6] I. Kopf, H.W.P. N'Dongo, F. Ballout, U. Schatzschneider, E. Bründermann, M. Havenith, "Introducing cymantrene labels into scattering scanning near-field infrared microscopy”, Analyst 137, pp. 4995-5001, 2012.

[7] E. Bründermann, H-W.Hübers, M.F. Kimmitt, Terahertz Techniques, in Springer Series in Optical Sciences, Berlin, Heidelberg, Springer-Verlag, vol. 151, 2012, pp. 1-383. 